\title{
Starvation enhances phosphorus removal from wastewater by the microalga Chlorella spp. co-immobilized with Azospirillum brasilense
}

\author{
Juan-Pablo Hernandez, Luz E. de-Bashan, Yoav Bashan* \\ Environmental Microbiology Group, Center for Biological Research of the Northwest (CIB), \\ P.O. Box 128, La Paz, B.C.S. 23000, Mexico
}

Received 17 January 2005; received in revised form 31 May 2005; accepted 1 June 2005

\begin{abstract}
In synthetic wastewater, growth and phosphorus absorption by two species of microalgae, Chlorella sorokiniana and Chlorella vulgaris, and in domestic wastewater by $C$. sorokiniana significantly enhanced after a starvation period of 3 days in saline solution, combined with co-immobilization with the microalgae growth-promoting bacterium (MGPB) Azospirillum brasilense Cd in alginate beads. Starvation of 5 days negatively affected the subsequent growth of $C$. vulgaris, but not of $C$. sorokiniana in fresh wastewater. Starvation of immobilized cultures of microalgae separately or microalgae with bacteria, followed by returning the immobilized cultures to the same wastewater did not enhance phosphorus absorption. However, a starvation period followed by subsequent submersion of the cultures in fresh wastewater allowed the continuation of phosphorus absorption. The best phosphorus removal treatment from a batch of synthetic or domestic wastewater was with tandem treatments of wastewater treatment with pre-starved, co-immobilized microalgae and replacement of this culture, after one cycle of phosphorus removal, with a new, similarly starved culture. This combination treatment with two cultures was capable of removing up to $72 \%$ of phosphorus from the wastewater. There was a direct correlation between the initial load of phosphorus in the domestic wastewater and the efficiency level of removal, being highest at higher phosphorus loads in coimmobilized cultures. This occurred for both immobilized and co-immobilized cultures. Further, the results showed that negative effects of starving the microalgae were mitigated by the application of the MGPB A. brasilense Cd. This is the first report of this capacity in Azospirillum sp. on a single-cell plant. This study showed that starvation periods, combined with co-immobilization with MGPB, have synergistic effects on absorption of phosphorus from wastewater and merits consideration in designing future biological treatments of wastewater.
\end{abstract}

(C) 2005 Elsevier Inc. All rights reserved.

Keywords: Azospirillum; Chlorella; Microalgae; Microbial immobilization; Phosphorus removal; Plant growth-promoting bacteria; Starvation; Wastewater treatment

\section{Introduction}

Microalgae Chlorella spp. are commonly used for tertiary wastewater biological treatment [1-4]. Although nitrogenous compounds are commonly removed, removal of phosphorus, the second most important nutrient in domestic wastewater, is far less efficient. Seldom is full removal of phosphorus

\footnotetext{
* Corresponding author. Fax: +52 6121254710.

E-mail address: bashan@ cibnor.mx (Y. Bashan).
}

possible by biological processes and usually only a small fraction of phosphorus compounds are removed [5,6].

In recent years, bacteria of the genus Azospirillum that are well known as plant growth-promoting bacteria (PGPB) in agriculture for numerous crop plants [7] are considered as a microalga growth-promoting bacterium (MGPB) [8,9]. One common strain, Azospirillum brasilense $\mathrm{Cd}$, is also capable of promoting many growth parameters of the unicellular microalgae Chlorella vulgaris and Chlorella sorokiniana [10], and change the cytology and lipid and pigment production of the microalga $[8,11,12]$. Additionally, growth promo- 
tion improved capabilities of microalgae to remove nutrients from natural domestic wastewater has been demonstrated [13]. The microbial carrier chosen in these studies were alginate beads. Immobilization of microalgae in polysaccharide gels is an experimental way to use these microorganisms for wastewater treatment $[14,15]$ because it reduces the major difficulty of collecting enormous populations of cells developed during the treatment, which hamper regular microalgae treatments $[3,16]$. Although the efficiency of removing phosphorus by the co-immobilized microorganisms is increased, it had not reached high values of removal. It was hypothesized that the cells became saturated with phosphorus before all the phosphorus in the wastewater was removed [13].

This study describes various attempts to enhance phosphorus removal from wastewater by adding a starvation period to normally grown cells and to phosphorus-saturated cultures, together with co-immobilization with a MGPB. It was hypothesized that starvation and co-immobilization will allow the microalgal culture to absorb more phosphorus and remove phosphorus from phosphorus-saturated cells. This allows the use of the same co-immobilized culture again. This procedure was demonstrated in domestic, municipal wastewater from the city of La Paz, B.C.S., Mexico and a synthetic wastewater.

\section{Materials and methods}

\subsection{Microorganisms}

Two species of unicellular microalgae, C. vulgaris Beijerinck (UTEX 2714, Austin TX) and C. sorokiniana Shih. et Krauss (UTEX 1602) were used. The microalgae growthpromoting bacterium A. brasilense Cd (DMS 1843, Braunschweig, Germany) was used for co-immobilization experiments with both microalgae species.

\subsection{Immobilization and starvation procedures}

The procedure of co-immobilizing these microorganisms in alginate beads and then growing and counting them in cultures was previously reported [13]. Briefly, the experiments were performed in inverted, $1000 \mathrm{ml}$ conical, glass bioreactors containing $600 \mathrm{ml}$ wastewater, equipped with bottom aeration controlled by a peristaltic pump $\left(31\right.$ air $\left.\min ^{-1} 1^{-1}\right)$ at $26 \pm 2{ }^{\circ} \mathrm{C}$ (equivalent to ambient temperature) with constant illumination of $60 \mu \mathrm{mol} \mathrm{m}^{-2} \mathrm{~s}^{-1}$ and $\mathrm{pH}$ of 6.8-7.0 [13]. A. brasilense was cultivated prior to immobilization by standard techniques for this species [17]. Starvation of cultures employed incubating the beads containing the microorganisms (after a single washing with $0.85 \% \mathrm{NaCl}$ ) in a new, sterile preparation of this saline solution at continuous light intensity of $60 \mu \mathrm{mol} \mathrm{m}{ }^{-2} \mathrm{~s}^{-1}$ at $26 \pm 2{ }^{\circ} \mathrm{C}$ for 3 days. Some experiments employed starvation for 5 days. The starvation periods and the scheme of each type of experiment are described in Table 1.
Table 1

Starvation periods imposed on co-immobilized cultures of Chlorella spp. and $A$. brasilense

\begin{tabular}{|c|c|c|c|c|}
\hline \multicolumn{2}{|c|}{ Initial treatment } & \multirow{2}{*}{$\begin{array}{l}\text { Starvation period } \\
\text { (h) }(0.85 \% \mathrm{NaCl})\end{array}$} & \multicolumn{2}{|l|}{ Final treatment } \\
\hline $\begin{array}{l}\text { Type of } \\
\text { water }\end{array}$ & $\begin{array}{l}\text { Time of } \\
\text { incubation } \\
\text { (h) }\end{array}$ & & $\begin{array}{l}\text { Type of } \\
\text { water }\end{array}$ & $\begin{array}{l}\text { Time of } \\
\text { incubation } \\
\text { (h) }\end{array}$ \\
\hline & None & 120 & New SW & 240 \\
\hline & None & 72 & New SW & 240 \\
\hline SW & 240 & 72 & New SW & 240 \\
\hline SW & 240 & 72 & The same SW & 240 \\
\hline SW & 48 & 72 & $\begin{array}{l}\text { New beads with } \\
\text { the same SW }\end{array}$ & 48 \\
\hline DW & 48 & 72 & $\begin{array}{l}\text { New beads with } \\
\text { the same DW }\end{array}$ & 48 \\
\hline
\end{tabular}

SW, synthetic wastewater; DW, domestic wastewater.

\subsection{Synthetic and municipal wastewater source}

The composition of synthetic wastewater was previously described [10]. Municipal domestic wastewater was collected periodically for every separate run of the bioreactors at the municipal wastewater treatment plant of the city of La Paz, Baja California Sur, Mexico. Samples were collected from a stream of wastewater after the initial aerobic activated sludge treatment and immediately transferred to the laboratory. If necessary, debris in the wastewater was filtered through a cotton gauze filter in a funnel. Wastewater was used as it arrived from the treatment plant. The levels of $\mathrm{NaCl}$ and phosphorus in the wastewater were insufficient to damage the beads. Alternatively, when wastewater arrived from the treatment plant with a low level of phosphorus compounds, the level of $\mathrm{P}$ was increased to a level of $20 \mathrm{mg} \mathrm{l}^{-1}$ by the addition of $\left(\mathrm{mg} \mathrm{l}^{-1}\right)$ : $\mathrm{KH}_{2} \mathrm{PO}_{4}(21.7), \mathrm{K}_{2} \mathrm{HPO}_{4}(8.5), \mathrm{Na}_{2} \mathrm{HPO}_{4}$ (33.4) and to $40 \mathrm{mg} \mathrm{l}^{-1}$ by $\mathrm{KH}_{2} \mathrm{PO}_{4}$ (43.4), $\mathrm{K}_{2} \mathrm{HPO}_{4}$ (17), $\mathrm{Na}_{2} \mathrm{HPO}_{4}$ (66.8). The arriving wastewater was filtered and sterilized, a process that caused sedimentation of some P. Therefore, after adding the sources of phosphorus listed above, the mixture was sterilized again, losing part of the added $\mathrm{P}$, but reaching the target $\mathrm{P}$ concentration in the solution. Wastewater was stored at $4{ }^{\circ} \mathrm{C}$ for several days as a precaution following the run of the bioreactors. The composition of the wastewater was previously described [13].

\subsection{Water analysis of treated wastewater}

Standard water analysis technique for phosphorus [18] was performed with a Hach DR/2000 spectrophotometer and Hach kits (Hach Co., Loveland, CO, USA).

\subsection{Experimental design and statistical analysis}

The experiments were performed in the bioreactors as described above. Each experiment was performed in triplicate, where one bioreactor served as a replicate. The experiment used batch cultures. Controls (beads without microorganisms, wastewater alone, and microalgae and bacteria 


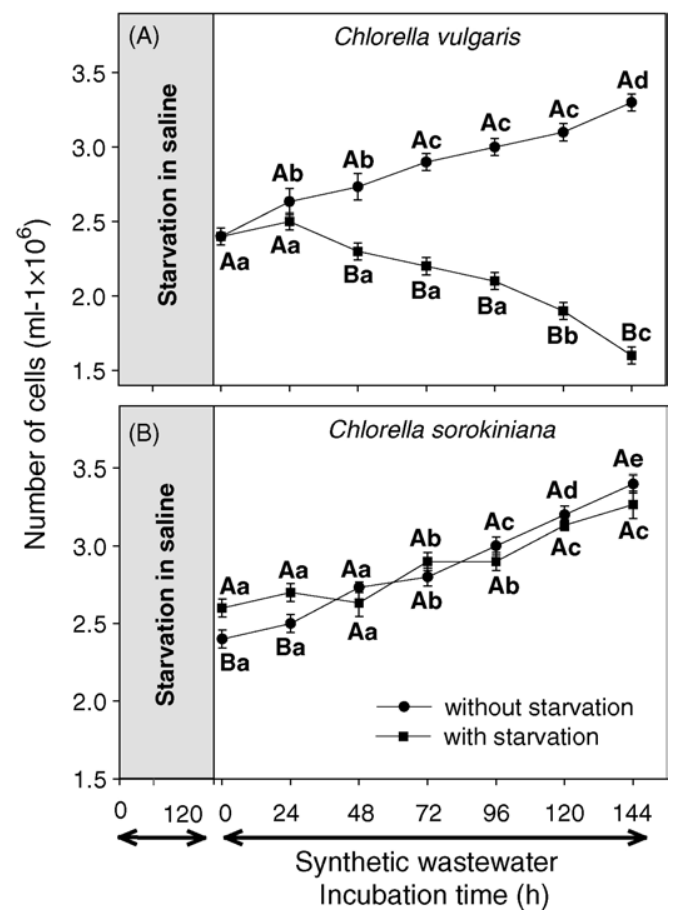

Fig. 1. Growth of C. vulgaris (A) and C. sorokiniana (B) immobilized separately in synthetic wastewater after starvation period in saline solution for 5 days. Points on curves denoted by a different lower case letter differ significantly by ANOVA at $P \leq 0.05$. Points at each time interval denoted by a different capital letter differ significantly by Student's $t$-test at $P \leq 0.05$. Bars represent standard error.

alone) were routinely used. Three $50 \mathrm{ml}$ samples were taken for each water analysis at each sampling time. Each experiment was repeated three times. Results were analyzed by ANOVA and Student's $t$-test, with significance at $P \leq 0.05$ using software package STATISTICA, Version 6 (StatSoft, Inc., Tulsa, OK, USA). As results were similar, only one representative experiment is presented.

\section{Results}

\subsection{Effect of starvation period on the population of $C$. vulgaris and C. sorokiniana and their capacity to remove phosphorus from synthetic wastewater}

A starvation period of 5 days irreversibly and negatively affected the population of $C$. vulgaris, which declined for $144 \mathrm{~h}$ into the experiment even though it was transferred into a fresh wastewater medium (Fig. 1A). The population of $C$. sorokiniana was unaffected and continued to grow similarly to non-starved culture (Fig. 1B, capital letters in statistical analysis). A starvation period of 3 days allowed $C$. vulgaris to recover part of its population size (Fig. 2A). However, co-immobilization with $A$. brasilense negatively affected the population level similar to a starvation period of 5 days (compare Fig. 2B with Fig. 1A). Three days starvation had only marginal effects on the population of $C$. sorokiniana. The immobilized and co-immobilized populations continued to grow after starvation but at a lower level (Fig. 2C and D).

The pattern of decline of phosphorus in synthetic wastewater differed from the growth pattern of the microalgae. Starved cells of $C$. vulgaris absorbed more phosphorus, but in smaller quantities in a gradual manner than non-starved cells after 48 and 144 of incubation (Fig. 3A). Starved cells of $C$. sorokiniana, on the other hand, absorbed significantly more phosphorus than non-starved cells during the experiment (Fig. 3B). Co-immobilization with A. brasilense changed this pattern for $C$. vulgaris. In co-immobilized cultures with $C$. vulgaris, significantly more phosphorus was removed after the first $48 \mathrm{~h}$. The level of removal stabilized thereafter and no additional phosphorus was removed. Co-immobilized, nonstarved cultures, although removing less phosphorus during the first $96 \mathrm{~h}$, continued to remove it during the entire $240 \mathrm{~h}$ trial and eventually removed more phosphorus than starved cells (Fig. 3C). Non-starved co-immobilized C. sorokiniana continuously removed phosphorus similar to $C$. vulgaris, but in lesser quantities (compare Fig. 3C and D). Starved coimmobilized $C$. sorokiniana responded in a similar pattern as starved C. vulgaris, but absorbed more phosphorus (Fig. 3D).

Calculating the maximum removal of $\mathrm{P}$ from the wastewater showed that immobilization with the MGPB, A. brasilense, significantly increased $\mathrm{P}$ absorption for both species of microalgae, both as a whole culture and absorption per single cell (Table 2). Starvation increased the $\mathrm{P}$ absorption of the culture further, but only for $C$. sorokiniana (Table 2). Starvation significantly increased efficiency of the single cells to absorb $\mathrm{P}$ and was in a range of $71-93 \%$ regardless of co-immobilization with $A$. brasilense (C. sorokiniana) and 12-109\% (C. vulgaris) where co-immobilization was the major factor (Table 2). Adding beads without microorganisms (control) did not affect phosphorus removal (Fig. 3A and B), while control of $A$. brasilense $\mathrm{Cd}$ alone did not remove measurable quantities of phosphorus (data not shown).

\subsection{Effect of changing the wastewater or the microbial culture on growth and removal of phosphorus by immobilized and co-immobilized cultures of $C$. sorokiniana subjected to starvation periods}

Immobilized cultures of $C$. sorokiniana, after normal growth (Fig. 4A) and subjected to 3 days starvation, declined in population (Fig. 4A). Co-immobilized cultures with $A$. brasilense $\mathrm{Cd}$ initially produced a larger microalgal population (Fig. 4A). When these cultures were starved, their populations did not decline further, but rather did not grow, and stayed constant (Fig. 4A). Cultures that were not starved continuously removed phosphorus for $240 \mathrm{~h}$, and co-immobilized cultures removed more (Fig. 4B). Starvation period and returning the cultures to the same wastewater blocked removal of phosphorus by immobilized or coimmobilized C. sorokiniana (Fig. 4B).

C. sorokiniana cultures (immobilized and co-immobilized, separately) that removed phosphorus in the usual man- 

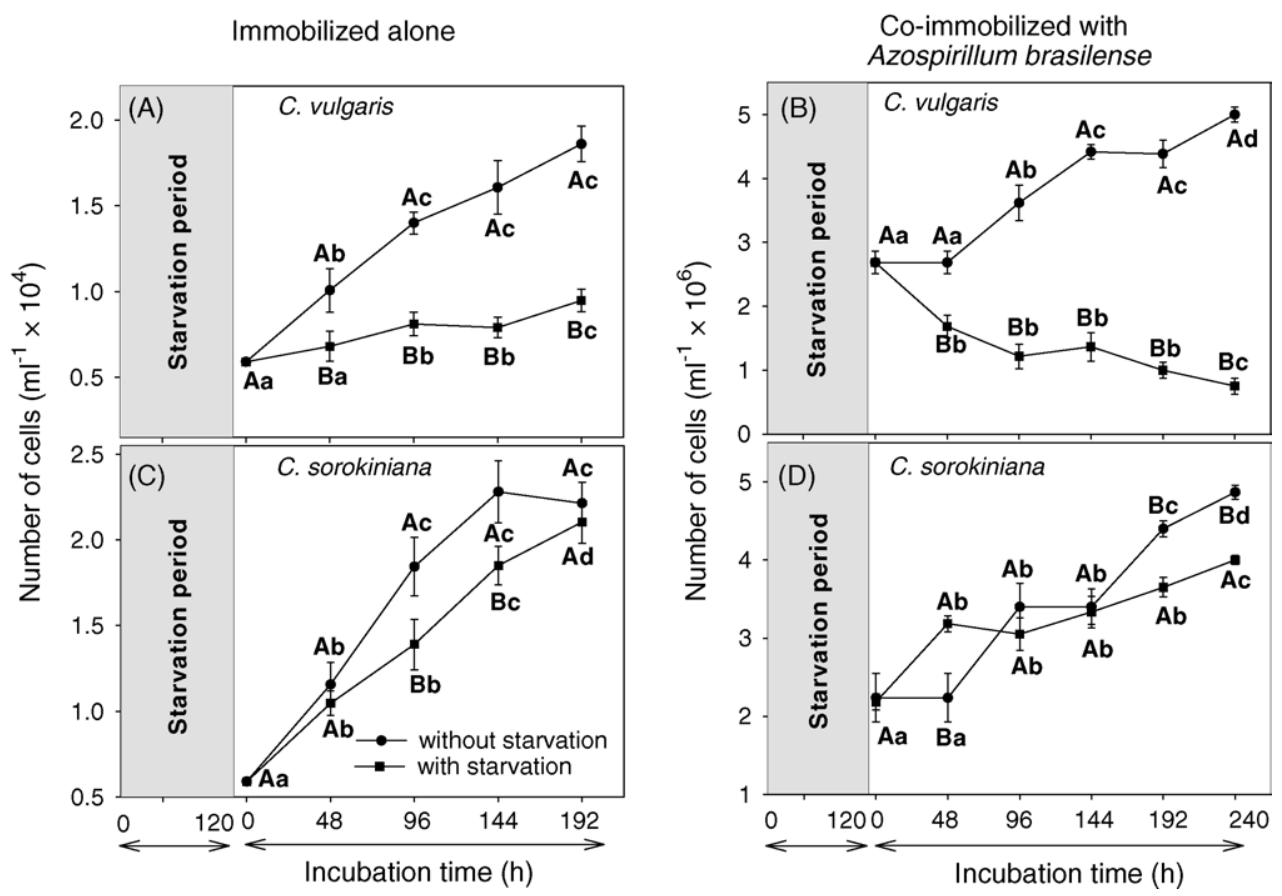

Fig. 2. Growth of C. vulgaris and C. sorokiniana immobilized separately (A and C) and co-immobilized with A. brasilense (B and D) in synthetic wastewater after starvation period in saline solution for 3 days. Points on curves denoted by a different lower case letter differ significantly by ANOVA at $P \leq 0.05$. Points at each time interval denoted by a different capital letter differ significantly with Student's $t$-test at $P \leq 0.05$. Bars represent standard error.

ner (Fig. 5A) were subjected to starvation for $72 \mathrm{~h}$ in saline and then were submerged in fresh wastewater. The two types of culture reacted differently to this condition. Immobilized culture continued to remove phosphorus from the new wastewater similar to cultures that were not starved, while coimmobilized cultures remove phosphorus for additional $48 \mathrm{~h}$ and then stopped (Fig. 5B). Yet, this removal was greater than removal of phosphorus by immobilized cultures.
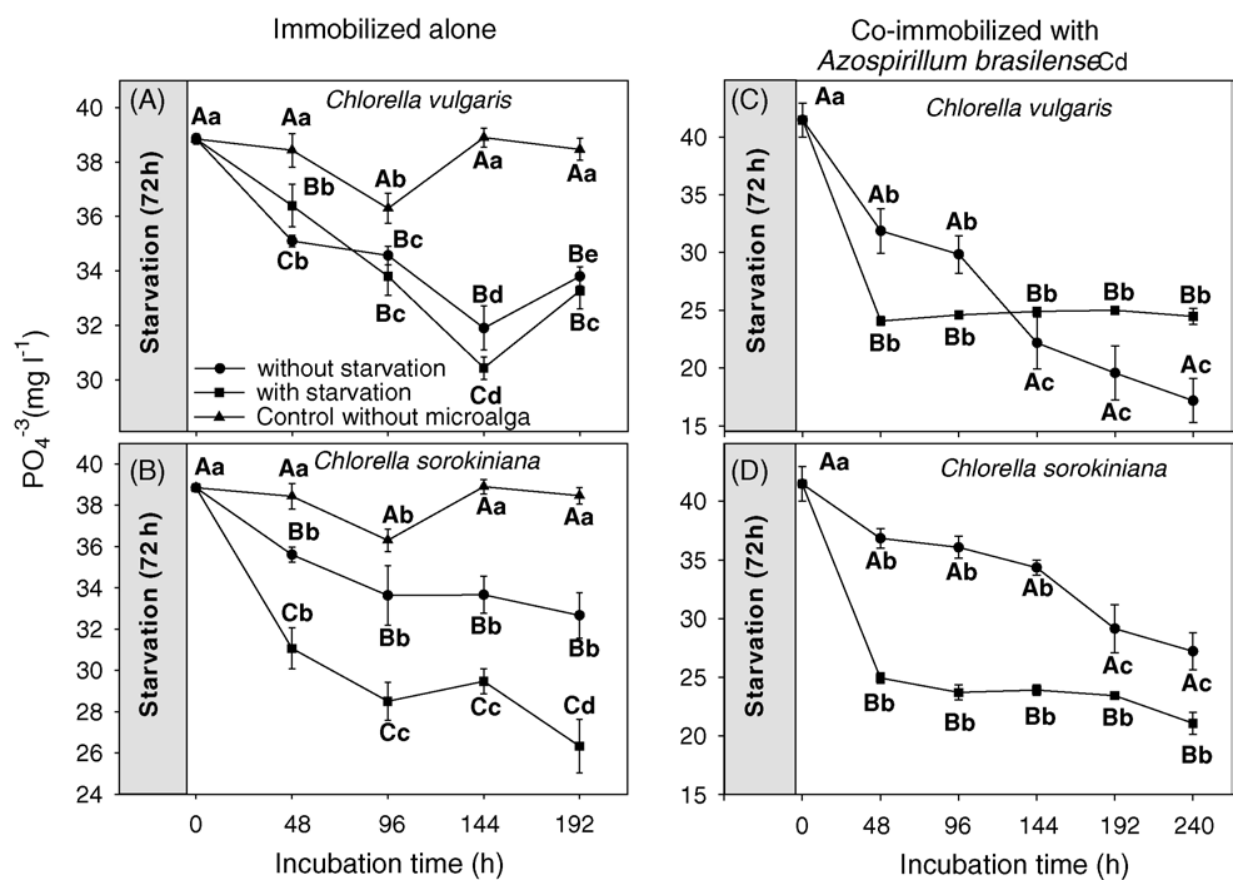

Fig. 3. Removal of phosphorus from synthetic wastewater by Chlorella spp. immobilized separately and co-immobilized with A. brasilense Cd. C. vulgaris (A and C) and C. sorokiniana (B and D). Points on curves denoted by a different lower case letter or italics lower case letter, separately, differ significantly by ANOVA at $P \leq 0.05$. Points at each time period denoted by a different capital letter differ significantly by ANOVA at $P \leq 0.05$ (A and B) and Student's $t$-test at $P \leq 0.05$ (C and D). Bars represent standard error. Absence of S.E. means a negligible S.E. $Y$-axis is different in each subfigure to enhance clarity. 
Table 2

Calculated maximum removal of phosphorus from synthetic wastewater by $C$. sorokiniana and $C$. vulgaris immobilized alone and co-immobilized with $A$. brasilense Cd under starvation

\begin{tabular}{|c|c|c|c|c|c|}
\hline \multirow[t]{2}{*}{ Microalgae } & \multirow{2}{*}{$\begin{array}{l}\text { Co-immobilization } \\
\text { with } A \text {. brasilense }\end{array}$} & \multirow{2}{*}{$\begin{array}{l}\text { Time of } \\
\text { incubation (h) }\end{array}$} & \multirow{2}{*}{$\begin{array}{l}\text { Starvation of } \\
72 \mathrm{~h} \text { in saline }\end{array}$} & \multicolumn{2}{|c|}{ Removal of $\mathrm{P}$ from wastewater per } \\
\hline & & & & Culture $\left(\mathrm{mg} 1^{-1}\right)^{\mathrm{a}}$ & Cell $\left(\mu \mathrm{g} \mathrm{cell}^{-1}\right)^{\mathrm{a}}$ \\
\hline C. sorokiniana & $\begin{array}{l}\text { None } \\
+ \\
\text { None } \\
+\end{array}$ & 192 & $\begin{array}{l}\text { None } \\
+\end{array}$ & $\begin{aligned} 6.18 & \pm 0.91 \mathrm{a} \\
12.33 & \pm 2.54 \mathrm{~b} \\
12.52 & \pm 1.5 \mathrm{~b} \\
18.30 & \pm 1.51 \mathrm{c}\end{aligned}$ & $\begin{aligned} 0.03 & \pm 0.06 \mathrm{a} \\
2.8 & \pm 1.8 \mathrm{~b} \\
0.07 & \pm 0.06 \mathrm{a} \\
4.94 & \pm 0.7 \mathrm{c}\end{aligned}$ \\
\hline C. vulgaris & $\begin{array}{l}\text { None } \\
+ \\
\text { None } \\
+\end{array}$ & 144 & $\begin{array}{l}\text { None } \\
+\end{array}$ & $\begin{aligned} 6.95 & \pm 1.02 \mathrm{a} \\
19.30 & \pm 2.37 \mathrm{~b} \\
8.42 & \pm 0.6 \mathrm{a} \\
16.57 & \pm 1.24 \mathrm{~b}\end{aligned}$ & $\begin{array}{l}0.04 \pm 0.004 \mathrm{a} \\
4.37 \pm 0.14 \mathrm{c} \\
0.01 \pm 0.002 \mathrm{a} \\
0.12 \pm 0.069 \mathrm{~b}\end{array}$ \\
\hline
\end{tabular}

\pm , S.E.

${ }^{a}$ Columns denoted by a different (a-c) lower case letter, for each microalgal species, separately, differ significantly by ANOVA at $P \leq 0.05$.

An attempt to enhance phosphorus removal by two successive treatments: first by initial starvation period of the co-immobilized culture, and then by subjecting the same wastewater to a new culture that also passed through a starvation period, significantly enhanced phosphorus removal from synthetic wastewater using co-immobilized cultures. Final phosphorus levels reached $12 \pm 2 \mathrm{mgl}^{-1}$ from initial concentration of $38 \mathrm{mg} \mathrm{l}^{-1}$ in the synthetic wastewater, removal of $69 \pm 2 \%$ (Fig. 6A). This double treatment served as a template for evaluating the system with domestic wastewater at three phosphorus loads, low, medium and high. When the initial level of phosphorus in the wastewater was low
(7.2 $\left.\mathrm{mg}^{-1}\right)$, the level of phosphorus after $96 \mathrm{~h}$ declined to $4.5 \mathrm{mgl}^{-1}$, correspond to a removal of $37.5 \%$ (Fig. 6B). Increased level of phosphorus in the wastewater change the removal to $45 \%$ for the wastewater with $22 \mathrm{mg}^{-1}$ phosphorus (22-12.3 $\mathrm{mg}^{-1}$ ) (Fig. 6C) and 72\% (45-12.3 $\mathrm{mg}^{-1}$ ) for the wastewater with $45 \mathrm{mg}^{-1}$ phosphorus (Fig. 6D). Although immobilization with $C$. sorokiniana also removed $P$ efficiently, the removal values were always smaller than with co-immobilization (Fig. 6A-D). C. sorokiniana, alone and co-immobilized with $A$. brasilense, increased during each cycle, but was significantly higher in co-immobilized culture (Fig. 6E, data shown only for high phosphorus load). There
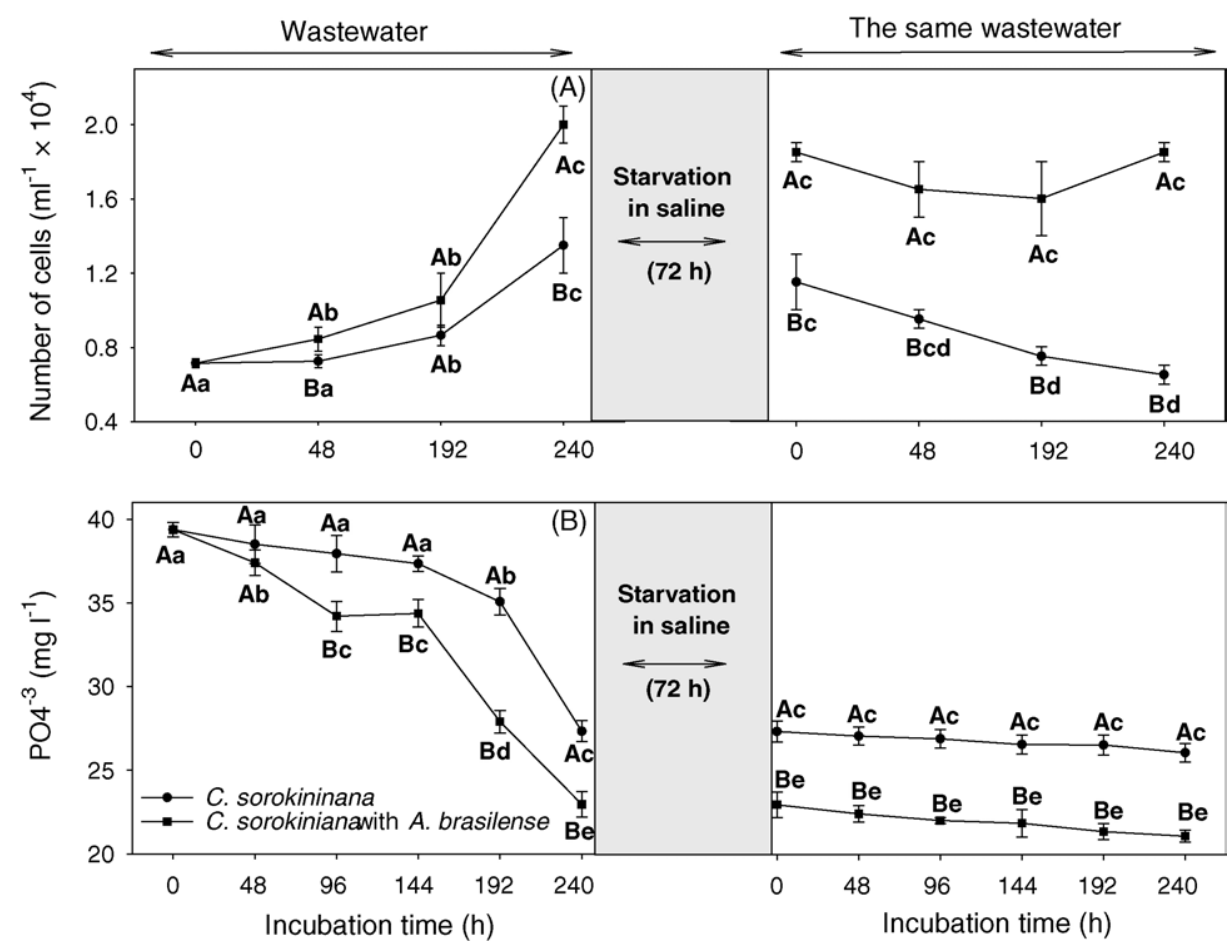

Fig. 4. (A) Growth and (B) removal of phosphorus from synthetic wastewater by C. sorokiniana separately and co-immobilized with A. brasilense Cd, after a starvation period in saline solution and returning the cultures to the same synthetic wastewater. Points on curves denoted by a different lower case letter differ significantly by ANOVA at $P \leq 0.05$. Points at each time interval denoted by a different capital letter differ significantly with Student's $t$-test at $P \leq 0.05$. Bars represent standard error. 


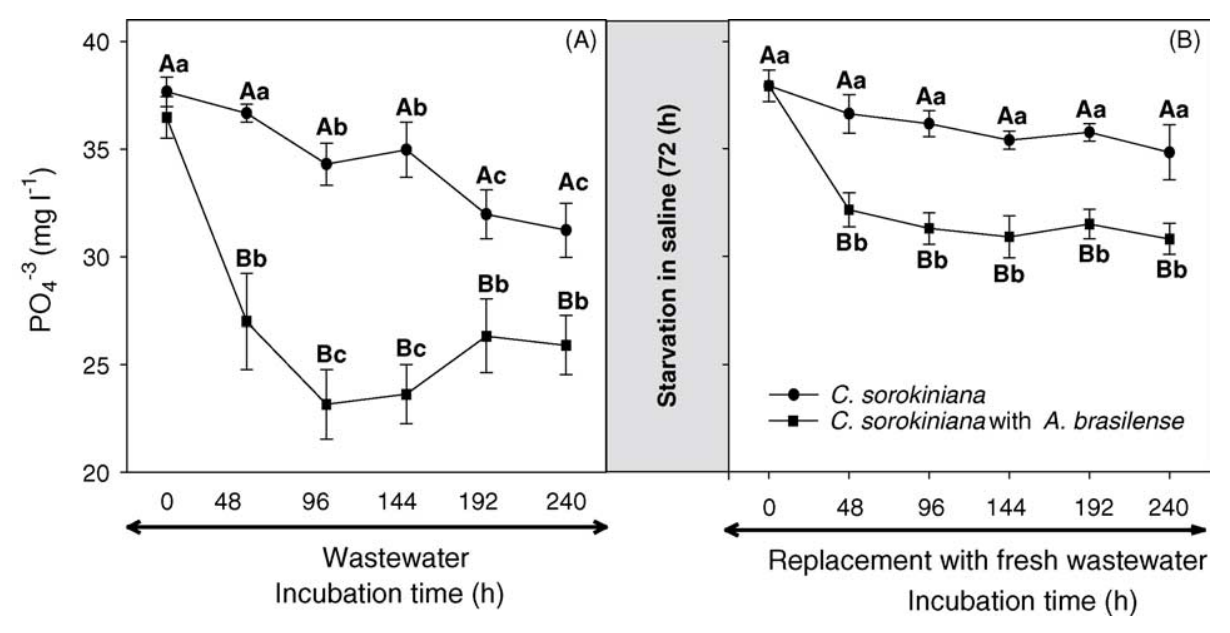

Fig. 5. Removal of phosphorus from synthetic wastewater, by $C$. sorokiniana separately and co-immobilized with A. brasilense Cd before (A) and after (B) a starvation period in saline solution and returning the cultures to a fresh synthetic wastewater. Points on curves denoted by a different lower case letter differ significantly by ANOVA at $P \leq 0.05$. Points at each time interval denoted by a different capital letter differ significantly with Student's $t$-test at $P \leq 0.05$. Bars represent standard error.

was a direct correlation between the initial load of $\mathrm{P}$ in the domestic wastewater and the level of removal, being higher at higher $\mathrm{P}$ load in co-immobilized cultures (Fig. 6F). This occurred for both immobilized and co-immobilized cultures $\left(r^{2}=0.93-0.99\right)$.

\section{Discussion}

Nitrogen and phosphorus starvation induced significant metabolic and physiological changes on microalgal cell. Starvation of nitrogen nutrients changed the photosynthetic efficiency of Dunaliella tertiolecta [19], enhanced adsorption of the cells to polymeric foams and increased N-uptake in Scenedesmus obliquus [20], and reduced biomass and growth rates together with increased crude lipid content in Olva pertusa [21]. Starvation of phosphorus nutrients increased the population upon re-exposure to wastewater in Scenedesmus bicellularis [22], changed the composition of fatty acids in the cells in $O$. pertusa [21] and temporarily enhanced P-uptake in Scenedesmus quadricauda [23]. During a period of phosphate starvation, the phosphate content of cells of $C$. vulgaris decreased especially inorganic polyphosphate [24], and several metabolic parameters were changed during phosphorus starvation in Chlorella kessleri [25].

So far, there is almost no report on complete removal of $\mathrm{PO}_{4}{ }^{3-}$, the main form of inorganic phosphorus used by algae, from domestic wastewater by biological wastewater treatment with in vitro small-scale experiments [5,26]. The microalgal cells apparently became saturated fast with $\mathrm{PO}_{4}{ }^{3-}$ $[4,13,26]$, probably due to accumulation of polyphosphates [27]. Furthermore, the preparation of co-immobilized cultures has a cost. Therefore, our working hypothesis to overcome these deficiencies were to subject the co-immobilized cultures to starvation periods aiming to increase $\mathrm{PO}_{4}{ }^{3-}$ absorption by the cells, and re-use of the same culture on a fresh wastewater upon "discharging" phosphorus from saturated cultures by starvation periods.

Starvation of immobilized microalga cultures differed in its effect between the two species of microalgae used concerning growth and their phosphorus absorption. In general, any starvation period declined the population of $C$. vulgaris. The 5 days starvation period had a detrimental and irreversible effect on the population. This resembled the effect of starvation on S. bicellularis [16]. However, the populations of both Chlorella spp. recovered after a shorter starvation period of 3 days, where $S$. bicellularis could not. On the other hand, the population growth of $C$. sorokiniana was less affected by starvation. Co-immobilization with the MGPB A. brasilense, that usually enhances growth of Chlorella spp. under normal growth conditions [10], had no positive effect on microalgae growth when the microalgae was treated to a short starvation period. For $C$. vulgaris, even a negative effect was present in the developing populations.

Starvation changed the pattern of $\mathrm{PO}_{4}{ }^{3-}$ absorption. In microalgae that were immobilized alone, $\mathrm{PO}_{4}{ }^{3-}$ absorption resembled known $\mathrm{PO}_{4}{ }^{3-}$ absorption of these cells [13,28]. However, starvation combined with co-immobilization with the MGPB A. brasilense Cd significantly increased $\mathrm{PO}_{4}{ }^{3-}$ absorption, being strongest during the first cycle of growth in the wastewater. This pattern resembled $\mathrm{PO}_{4}{ }^{3-}$ uptake by S. quadricauda grown alone in batch cultures [23].

Manipulating starvation periods, changes of wastewater, and changes of immobilized cultures treating the same wastewater all had effects on $\mathrm{PO}_{4}{ }^{3-}$ absorption and eventual removal from the wastewater. This study demonstrates that there is a synergism in $\mathrm{PO}_{4}{ }^{3-}$ absorption, at the culture and the single cell level, between co-immobilization of microalgae and imposed starvation. This combination significantly increased $\mathrm{PO}_{4}{ }^{3-}$ absorption in C. sorokiniana. The most successful treatment, in both synthetic wastewater and domestic wastewater, was enhanced phosphorus removal by subjecting 

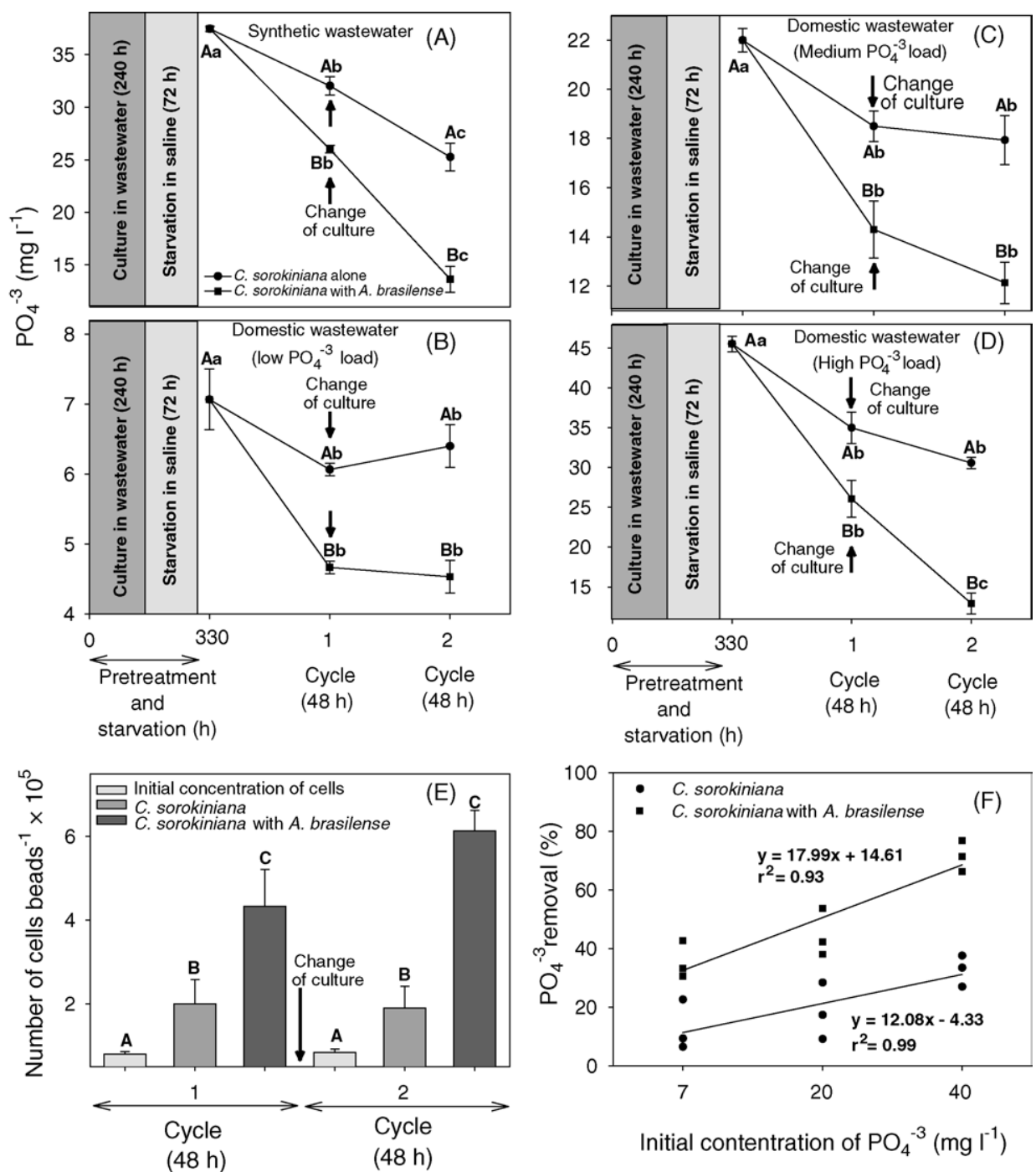

Fig. 6. Removal of phosphorus from synthetic (A) and three different $\mathrm{P}$ concentrations in municipal wastewater, low (B), medium (C) and high (D) by $C$. sorokiniana separately and co-immobilized with $A$. brasilense $\mathrm{Cd}$. The treatment followed the incubation scheme: culturing in wastewater, starvation, change to fresh wastewater for one cycle, and then subjecting the same wastewater to a different immobilized starved culture. Points on curves denoted by a different lower case letter differ significantly by ANOVA at $P \leq 0.05$. Points at each time interval denoted by a different capital letter differ significantly with Student's $t$-test at $P \leq 0.05$. (E) Population levels of $C$. sorokiniana in the two cycles described in (D). Columns in each cycle denoted by a different capital letter differ significantly by ANOVA at $P \leq 0.05$. Bars represent standard error. (F) Linear regression analyses between the initial $\mathrm{P}$ concentration in the wastewater and the percentage of removal achieved with this treatment. Absence of S.E. means a negligible S.E.

the same wastewater to two different co-immobilized cultures of $C$. sorokiniana, each culture subjected to a starvation period in tandem. This removed $69 \%$ of $\mathrm{PO}_{4}{ }^{3-}$ from the synthetic wastewater and $37.5 \%$ from domestic wastewater with low $\mathrm{PO}_{4}{ }^{3-}$ loads, and up to $72 \%$ from domestic wastewater with high $\mathrm{PO}_{4}{ }^{3-}$ concentrations. These results demonstrate significant improvement of absorption of phosphorus from authentic wastewater, comparable to or better than previous studies that demonstrated uptake efficiency of 44 [26] and $22 \%$ for C. vulgaris, and $36 \%$ for C. sorokiniana [13]. Additionally, this study demonstrated that phosphorus is removed from wastewater in a linear way based on the initial concentration of phosphorus in the domestic wastewater. Removal declines with time and with the reduction of phosphorus in the wastewater. The low efficiency of phosphorus uptake at low phosphorus concentration was demonstrated in earlier in vitro trials, but on a very small-scale [26].

Indigenous microflora of the domestic wastewater was not analyzed in detail in this study. There are always a large number of bacteria in wastewater samples. However, it was previously shown that several other semi-continuous treatment schemes did not yield significant removal of nutrients by the native microflora [13]. Additionally, the short time of the experiments (only two cycles of $48 \mathrm{~h}$ each) was insufficient to induce destabilization of the alginate beads by the presence of phosphorus ions.

It appears that the negative effects of starvation on growth and phosphorus absorption were mitigated by the application 
of the MGPB A. brasilense Cd, except in severe starvation episodes lasting 5 days. This agrees with the known capacity of Azospirillum spp. to mitigated several other environmental stresses on higher plants, such as drought [29,30], salt [31-33] and humic acids [34]. This is the first report that this beneficial capacity of Azospirillum sp. was demonstrated on single-cell microalgae.

\section{Conclusions}

Starvation periods ( 3 or 5 days in saline solution) significantly affected the growth and phosphorus absorbing capabilities of two species of microalgae, $C$. vulgaris and C. sorokiniana. Starvation enhanced $\mathrm{PO}_{4}^{-3}$ absorption by $C$. sorokiniana and co-immobilization with the MGPB A. brasilense further enhanced $\mathrm{PO}_{4}{ }^{3-}$ absorption. Increased efficiency in removing $\mathrm{PO}_{4}{ }^{3-}$ from wastewater can be accomplished by a combination of starvation, co-immobilization with MGPB, and changing the cultures that treat wastewater.

\section{Acknowledgements}

We thank Abigail Solano and Juana Solano from the municipal wastewater treatment plant of $\mathrm{La} \mathrm{Paz}$ for free access to their facility, the staff editor at CIB for improving the English text, and an anonymous reviewer of our previous publication in Water Research who proposed this line of research. This study was partially supported by SEMARNAT, Mexico (grant 2002-C01-0005) and by the Bashan Foundation, USA. Yoav Bashan participated in this study in the memory of the late Messrs. Avner Bashan and Uzi Bashan of Israel.

\section{References}

[1] de la Noüe J, De Pauw N. The potential of microalgal biotechnology: a review of production and uses of microalgae. Biotechnol Adv 1988;6:725-70.

[2] Gonzalez LE, Cañizares RO, Baena S. Efficiency of ammonia and phosphorus removal from a Colombian agroindustrial wastewater by the microalgae Chlorella vulgaris and Scenedesmus dimorphus. Bioresour Technol 1997;60:259-62.

[3] Tam NFY, Wong YS. Effect of immobilized microalgal bead concentration on wastewater nutrient removal. Environ Pollut 2000;107:145-51.

[4] Valderrama LT, Del Campo CM, Rodriguez CM, de-Bashan LE, Bashan Y. Treatment of recalcitrant wastewater from ethanol and citric acid production using the microalga Chlorella vulgaris and the macrophyte Lemna minuscula. Water Res 2002;36:4185-92.

[5] de-Bashan LE, Bashan Y. Recent advances in removing phosphorus from wastewater and its future use as fertilizer (1997-2003). Water Res 2004;38:4222-46.

[6] Galarneau E, Gehr R. Phosphorus removal from wastewaters: experimental and theoretical support for alternative mechanisms. Water Res 1997;31:328-38.

[7] Bashan Y, Holguin G, de-Bashan LE. Azospirillum-plant relationships: physiological, molecular, agricultural, and environmental advances (1997-2003). Can J Microbiol 2004;50:521-77.
[8] de-Bashan LE, Bashan Y, Moreno M, Lebsky V, Bustillos JJ. Increased in pigment and lipid content, lipid variety, and cell and population size of the microalgae Chlorella spp. when coimmobilized in alginate beads with the microalgae-growth-promoting bacterium Azospirillum brasilense. Can J Microbiol 2002;48:514-21.

[9] de-Bashan LE, Bashan Y. Microalgae growth-promoting bacteria: a novel approach in wastewater treatment. Revista Colombiana de Biotecnologia 2003;5:85-90 [in Spanish].

[10] Gonzalez LE, Bashan Y. Increased growth of the microalga Chlorella vulgaris when coimmobilized and cocultured in alginate beads with the plant growth-promoting bacterium Azospirillum brasilense. Appl Environ Microbiol 2000;66:1527-31.

[11] Gonzalez-Bashan LE, Lebsky V, Hernández JP, Bustillos JJ, Bashan Y. Changes in the metabolism of the microalgae Chlorella vulgaris when coimmobilized in alginate with the nitrogen-fixing Phyllobacterium myrsinacearum. Can J Microbiol 2000;46:653-9.

[12] Lebsky V, Gonzalez-Bashan LE, Bashan Y. Ultrastructure of interaction in alginate beads between the microalga Chlorella vulgaris with its natural associative bacterium Phyllobacterium myrsinacearum and with the plant growth-promoting bacterium Azospirillum brasilense. Can J Microbiol 2001;47:1-8.

[13] de-Bashan LE, Hernandez JP, Morey T, Bashan Y. Microalgae growth-promoting bacteria as "helpers" for microalgae: a novel approach for removing ammonium and phosphorus from municipal wastewater. Water Res 2004;38:466-74.

[14] Chevalier P, de la Noüe J. Wastewater nutrient removal with microalgae immobilized in carrageenan. Enzyme Microbiol Tech 1985;7:621-4.

[15] Lau P, Tam NFY, Wong YS. Wastewater nutrients ( $N$ and $\mathrm{P}$ ) removal by carrageenan and alginate immobilized Chlorella vulgaris. Environ Technol 1997;18:893-9.

[16] Kaya VM, de la Noüe J, Picard G. A comparative study of four systems for tertiary wastewater treatment by Scenedesmus bicellularis: new technology for immobilization. J Appl Phycol 1995;7:8595.

[17] Bashan Y, Holguin G, Lifshitz R. Isolation and characterization of plant growth-promoting rhizobacteria. In: Glick BR, Thompson JE, editors. Methods in plant molecular biology and biotechnology. Boca Raton, FL: CRC Press; 1993. p. 331-45.

[18] Standard methods for the examination of water and wastewater. 18th ed. Washington, DC: APHA, AWWA, WPCF (American Public Health Association, American Waterworks Association, Water Pollution Control Federation); 1992. p. 1105.

[19] Berges JA, Charlebois DO, Mauzerall DC, Falkowski PG. Differential effects of nitrogen limitation on photosynthetic efficiency of photosystems I and II in microalgae. Plant Physiol 1996;110:689-96.

[20] Urrutia I, Serra JL, Llama MJ. Nitrate removal from water by Scenedesmus obliquus immobilized in polymeric foams. Enzyme Microb Tech 1995;17:200-5.

[21] Floreto E, Teshima S, Ishikawa M. Effects of nitrogen and phosphorus on the growth and fatty-acid composition of Ulva pertusa Kjellman (Chlorophyta). Bot Mar 1996;39:69-74.

[22] Kaya VM, Picard G. The viability of Scenedesmus bicellularis cells immobilized on alginate screens following nutrient starvation in air at 100 percent relative humidity. Biotechnol Bioeng 1995;46:459-64.

[23] Jansson M. Uptake, exchange, and excretion of orthophosphate in phosphate-starved Scenedesmus quadricauda and Pseudomonas K7. Limnol Oceanog 1993;38:1162-78.

[24] Aitchison PA, Butt VS. The relation between the synthesis of inorganic polyphosphate and phosphate uptake by Chlorella vulgaris. $\mathrm{J}$ Expt Bot 1973;24:497-510.

[25] El-Sheek MM, Rady AA. Effect of phosphorus starvation on growth, photosynthesis and some metabolic processes in the unicellular green alga Chlorella kessleri. Phyton 1995;35:139-51.

[26] Robinson PK, Reeve JO, Goulding KH. Phosphorus uptake kinetics of immobilized Chlorella in batch and continuous-flow culture. Enzyme Microb Tech 1989;11:590-6. 
[27] Darley WM. Algal biology: a physiological approach. Blackwell Scientific Publications; 1987, 236 pp

[28] de-Bashan LE, Moreno M, Hernandez JP, Bashan Y. Removal of ammonium and phosphorus ions from synthetic wastewater by the microalgae Chlorella vulgaris coimmobilized in alginate beads with the microalgae growth-promoting bacterium Azospirillum brasilense. Water Res 2002;36:2941-8.

[29] Creus CM, Sueldo RJ, Barassi CA. Water relations in Azospirilluminoculated wheat seedlings under osmotic stress. Can J Bot 1998;7:238-44.

[30] Sarig S, Okon Y, Blum A. Promotion of leaf area development and yield in Sorghum bicolor inoculated with Azospirillum brasilense. Symbiosis 1990;9:235-45.
[31] Bacilio M, Rodriguez H, Moreno M, Hernandez JP, Bashan Y. Mitigation of salt stress in wheat seedlings by a $g f p$-tagged Azospirillum lipoferum. Biol Fertil Soils 2004;40:188-93.

[32] Creus C, Sueldo R, Barassi CA. Shoot growth and water status in Azospirillum-inoculated wheat seedlings grown under osmotic and salt stresses. Plant Physiol Biochem 1997;35:939-44.

[33] Hamdia MA, El-Komy HM. Effect of salinity, gibberellic acid and Azospirillum inoculation on growth and nitrogen uptake of Zea mays. Biol Plant 1997;40:109-20.

[34] Bacilio M, Vazquez P, Bashan Y. Alleviation of noxious effects of cattle ranch compost on wheat seed germination by inoculation with Azospirillum spp. Biol Fertil Soils 2003;38:261-6. 